\title{
O Trabalho Interdisciplinar como Modo de Humanização do Cuidado em um Grupo de Pacientes Amputados
}

\author{
Ortiz, Marta Cristina Meirelles; Taba, Gisele Paiva Fernanda Maiyumi; Ribeiro, \\ Larissa Araujo; Mattos, Luísa de; Pereira, Graziani Renata Sasdelli Silva; \\ Ogawa, Vivian Miwa \\ Unifesp - Baixada Santista — martacris_o@outlook.com
}

Perder um membro gera mudanças bruscas que remetem à necessidade de reconstrução da imagem corporal e da identidade por parte do sujeito. Dolto (1992) distingue esquema corporal, o corpo em sua realidade física, e imagem inconsciente do corpo, fruto da história pessoal, síntese das vivências inter-humanas fundamentais do sujeito. uma transformação do esquema corporal por lesão deve ser acompanhada da elaboração subjetiva das vivências experimentadas nesse processo, de modo a reconstruir a imagem corporal. o grupo constitui um espaço de circulação de palavras e afetos que favorece a elaboração subjetiva, contribuindo de modo significativo para a tal reconstrução. Nessa perspectiva trabalhou-se com um grupo de pacientes que tiveram membros superiores amputados, em parte ou totalmente, atendido pelo Ambulatório de Terapia de Mão de um grande hospital. As atividades foram desenvolvidas por estagiários dos cursos de Terapia Ocupacional e de Psicologia de uma universidade pública, com base no princípio pedagógico de formação de profissionais voltados para o trabalho interdisciplinar e humanização da saúde. Objetivos: Geral: Oferecer a um grupo de pacientes amputados um tratamento que vá além da reabilitação física, identificando e propondo respostas a demandas que não são apenas da doença ou do trauma físico, mas interferem no tratamento e, mais ainda, na vida do sujeito como um todo. Específicos: (1) Tornar o grupo de reabilitação um espaço de identificação com o outro, troca de experiências, acolhimento, socialização, ampliação da rede de suporte social entre os participantes, favorecendo a reconstrução de sua imagem corporal. (2) Proporcionar aos alunos de ambos os cursos a possibilidade de integração entre teoria e prática, por lidar direta e pessoalmente com as questões ligadas à intedisciplinaridade e à intersubjetividade nas relações que envolvem equipes de saúde, profissionais e pacientes no contexto da instituição hospitalar. Resultados: Durante 20 encontros foram realizadas atividades integradas de Terapia Ocupacional e Psicologia, nas quais foram trabalhadas questões relativas à imagem corporal e identidade e sintomas oriundos da amputação, seu tratamento e possíveis adaptações. Durante a realização de um bloco de dinâmicas relacionadas a autoimagem e identidade, surgiram temas referentes à auto estima, vergonha, dificuldade de olhar para o coto e culpa, que se refletem no convívio social e nas relações familiares. Conclusão: As atividades integradas entre os estágios de Psicologia e de Terapia Ocupacional, com preceptoria e supervisão por parte de profissionais do serviço e docentes da universidade, comprovou a importância de um trabalho interdisciplinar com os pacientes amputados. Considerase também a continuidade e ampliação do trabalho, comparticipação de profissionais e/ou estudantes do curso de Serviço Social. Assim os aspectos social, físico e emocional poderão ser cuidados de modo mais efetivo, integral e humanizado.

Ortiz, Marta Cristina Meirelles; Taba, Gisele Paiva Fernanda Maiyumi; Ribeiro, Larissa Araujo; Mattos, Luísa de; Pereira, Graziani Renata Sasdelli Silva; Ogawa, Vivian Miwa. O Trabalho Interdisciplinar como Modo de Humanização do Cuidado em um Grupo de Pacientes Amputados. In: Anais do Congresso Internacional de Humanidades \& Humanização em Saúde [= Blucher Medical Proceedings, num.2, vol.1]. São Paulo: Editora Blucher, 2014. ISSN 23577282, DOI 10.5151/medpro-cihhs-10400 